\section{Democracia por entre classes e raças}

Antonio Sérgio Alfredo GUIMARÃES. Classes, raças e democracia. São Paulo, Editora 34, 2002. 231 páginas.

\section{Omar Ribeiro Thomaz}

Respeite meus cabelos, brancos Chico César

O Brasil mudou. E mudou ali onde, ao longo de décadas, suspeitou-se que estaríamos diante do irredutivel: aquelas representações que afirmavam traduzir o que seria a nossa identidade nacional. Como numa espécie de suspensão do tempo, imaginou-se, durante décadas, um Brasil que se realizaria no espaço, e que não seria outro se não o país que resultasse do encontro das três raças constitutivas de nossa nacionalidade. Podemos afirmar, sem medo, a existência de uma longa tradição discursiva (e política) que predestinava o Brasil à superação de sua marca de origem, a violência inerente ao sistema escravista, estando assim a construção da nação condenada a superar a distância inicial imposta aos grupos formadores. É Gilberto Freyre quem cria um verdadeiro esquema espacial e funcional numa forma mais acabada, o qual representaria a superação da distância existente entre a casa-grande e a senzala, entre o sobrado e o mocambo, num processo social específico, a mestiçagem. Ao mulato caberia a redenção de nossa história que, diga-se de passagem, foi descrita por Freyre em sua obra magistral nos anos de 1930 como violenta e prenhe de conflitos.

De teoria do Brasil à ideologia, de interpretação do país à cultura nacional, a democracia social de Freyre, transformada em democracia racial, parecia ter vindo para ficar. Em todo caso, como tudo aquilo que chega em sua casa e parece se eternizar, tal interpretação não deixou de provocar incômodos desde o princípio. Já nos anos de 1930 e 1940, várias vozes levantaram-se no sentido de criticar essa visão autocomplacente que passara a predominar entre nós, e que teve conseqüências em projetos políticos e nas instituições. A percep- ção de que estaríamos diante de um mito não esfriou as críticas advindas dos movimentos negros que se espalharam pelo país, nem as da academia, e as representações paradoxais que surgiam nos tratados sobre identidade nacional, nas artes, na literatura ou nas manifestações da cultura popular acabaram por constituir uma arena de debate. Eis o Brasil repetidamente confirmado como nação naquilo que caracteriza essas entidades políticas modernas: antes de serem um produto material acabado, ou uma realidade social transparente, parece que temos diante de nós um debate sem fim, um foco virtual a orientar projetos e ansiedades, instituições e expectativas, interpretações do passado e projeções de futuro.

Antônio Sérgio Guimarães não se furta em nenhum momento à complexidade que se desenha diante de seus olhos. Num conjunto de ensaios que supera as fronteiras existentes entre as ciências sociais, o autor digladia-se igualmente com a literatura propriamente sociológica e a que viria de uma tradição antropológica, com as vozes que vêm da arte e da literatura e aquela que se apresenta como proveniente de movimentos sociais. Afinal de contas, de identidade nacional se trata, e sobre ela, incluídos e excluídos, ricos e pobres, "brancos" e "negros", todos temos algo a dizer.

Os principais interlocutores de Antônio Sérgio são, com toda a certeza, de duas ordens distintas. De um lado, seus pares: sociólogos e antropólogos; de outro, e em pé de igualdade, a inteligentsia vinculada aos movimentos sociais no Brasil, particularmente os movimentos negros. Para estes, o mito de democracia racial tornar-seia seu principal alvo, assim como para a literatura especializada, de forma evidente a partir da década de 1970 e do acirramento das lutas pela democratização do país. Contra a ordem harmoniosa e não-conflitiva pintada pelo enredo mítico, ergue-se a fala desmistificadora que revela a sociedade brasileira tal como ela é: racista e discriminadora. A democracia racial teria se tornado uma espécie de instrumento ideológico que legitima as desigualdades e impede a transformação. ${ }^{1}$

Numa leitura certamente interessada, já comum em nossa tradição intelectual, dois momentos se destacam: a década de 1930 e Gilberto Freyre, momento em que o mito é construído, e 
os anos de 1950, quando, sob a batuta de Florestan Fernandes e Roger Bastide, de um lado, e Guerreiro Ramos e Costa Pinto, de outro, denuncia-se o preconceito e a discriminação, ainda que sob pena de a questão racial ter-se reduzido à problemática de classes.

E é justamente tendo como ponto de partida o conceito de classe social - e seus desdobramentos na sociologia no Brasil - que Antônio Sérgio Guimarães inicia esta coletânea de ensaios que, arrisco, veio para ficar. Para além do rigor conceitual anunciado logo no primeiro momento - o que em seus próprios termos garante a perenidade de um trabalho sociológico - o conjunto dos ensaios é o que melhor representa o terremoto que, há pelo menos uma década, tem contemplado o panorama das ciências sociais no Brasil, prenunciado na necessidade de revisitar a nossa tradição intelectual, rever os clássicos, renovar sua leitura e, de quebra, chacoalhar os lugares comuns que dominam qualquer universo social como lembra Bourdieu, o mundo intelectual é um mundo social como qualquer outro. E mais: se desejamos uma sociedade mais justa, devemos (nós, da universidade) repensar a nossa já histórica relação com outros grupos sociais - nomeadamente movimentos sociais, sindicatos e organizações políticas - e com o Estado.

O problema é ainda mais intrincado, pois os dois conceitos iniciais que orientam a análise de Antônio Sérgio, "classe social" e "raça", são, como de praxe, importados. Importados de tradições sociológicas hegemônicas que pautaram a consolidação da moderna sociologia entre nós (poderia ser de outra forma?) e de tradições culturais e políticas estrangeiras não menos hegemônicas. À crítica de que o conceito de classe social não dá conta da particularidade da reprodução da desigualdade social e da pobreza entre nós - o que exige sua revisão, tema do primeiro capítulo - sobrepõe-se o desconforto suposto numa idéia de "raça" (sempre entre "aspas") que parece distante do universo social brasileiro - tema do livro como um todo, mas particularmente do capítulo 2. Ciente desse desconforto, sobre o qual muito tem sido escrito nos últimos anos, Antônio Sérgio enfrenta o problema da seguinte forma: a percepção sociológica do caráter questionável do conceito de "raça" não implica seu abandono como categoria social que opera nas relações sociais.

O dilema não é menos aflitivo do que aquele enfrentado por Vicent Capranzano no início da década de 1980, quando procurava, a partir de um procedimento etnográfico, compreender a instituição do poder do ponto de vista dos poderosos na África do Sul então dominada pelo apartheid. ${ }^{2}$ A proposta implicava uma aproximação ao mundo dos "brancos", divididos entre anglófonos e boers. A crítica ao apartheid, por parte do antropólogo, começava numa tentativa de se afastar de categorias como "negros", "brancos", "indianos" ou "coloured" - tratava-se afinal de classificações criadas pelo apartheid para garantir sua perpetuação. No momento de construir o texto, Capranzano não conseguiu escapar dos termos por ele criticados, pois se encontrara com um mundo social efetivamente dividido entre "brancos", "negros", "indianos" e "coloureds".

Lidamos com um dilema pelo menos análogo no Brasil? Um conceito como o de "raça", criticado há pelo menos um século por uma vigorosa tradição antropológica, poderia ser incorporado como uma categoria social? Antônio Sérgio encontra-se em meio a um debate, que é recuperado ao longo dos seus ensaios, em especial no capítulo 2, quando o autor dá voz aos seus críticos. A idéia de "raça" como um conceito nativo que não poderia ser assim incorporado como categoria sociológica, ou a noção (esta sim muito presente na academia brasileira) de que se trataria da manipulação de um jogo dual de classificações devedor de uma realidade estrangeira, particularmente dos Estados Unidos, constituem argumentos respondidos pelo autor quando procura apresentar as linhas que conduzem a discussão em torno do racialismo. Antônio Sérgio incorpora ainda as críticas daqueles que vêm na noção de "raça" algo carregado de um sentido histórico preciso, claramente devedor da biologia ou da genética.

O que parece que deveria constituir um objeto mais sistemático de análise, ou dúvida, diz respeito à afirmação de que a noção de "raça", como conceito nativo, é realmente operativa para compreender a realidade brasileira. Se é evidente que estamos num país numericamente dividido pelo censo como sendo formado por "brancos", 
"pretos", "pardos", "amarelos" e "índios", e que é percebido por setores dos movimentos negros e por alguns intelectuais como pautado pela existência de "negros" e "brancos", valeria a pena lembrar aqueles que insistem na evidência de uma dinâmica social pautada pela ambigüidade quanto às classificações baseadas em fenótipo ou origem. Injusto seria dizer que Antônio Sérgio não tem em conta autores como Peter Fry, Yvonne Maggie ou Mônica Grin. Parece no entanto que deveríamos levar adiante esta reflexão, que, por outro lado, não coloca em xeque a proposta do autor, particularmente no que diz respeito às análises que têm a pobreza como questão.

De certa forma, essa ambigüidade está presente quando Antônio Sérgio incorpora em sua análise uma reflexão sobre os "baianos" da cidade de São Paulo. Se é evidente que a clara percepção de que estamos diante de uma violenta discriminação de um grupo balança os alicerces de uma nação que se queria étnica e regionalmente harmônica, não é menos claro que um grupo como o dos "baianos" nos obriga a rever rígidas categorias pautadas pela idéia de "raça". Aqui, ao fenótipo se somam outras características cruciais para definir a experiência da discriminação, como gestos, sotaques etc.

Por fim, ao enfrentar o mito por sua negação cotidiana, o insulto racial, Antônio Sérgio apresenta um dos ensaios mais luminosos desta coletânea, o qual deve (eu espero) render múltiplas etnografias e estudos de caso, pelas questões que levanta. O insulto racial constitui um dos rituais mais perversos do nosso cotidiano, representando uma dimensão essencial das relações entre os grupos sociais no Brasil, e revela uma dimensão privada nem sempre bem trabalhada pelas ciências sociais: o sofrimento individual como esfera decisiva na criação de subjetividades e na reprodução de jogos sociais. Sua porta de entrada são as demandas apresentadas na Delegacia de Crimes Raciais da cidade de São Paulo, o que, em princípio, oferece certas limitações, para as quais o autor está absolutamente atento. A primeira diz respeito à premissa de que o insulto racial, que nos envolve a todos, possíveis insultantes e possíveis insultados, desde a mais tenra idade, pode se traduzir numa demanda judicial. A tentativa de iluminar o processo de insulto por meio do expediente judicial, o qual, por definição, recorta o conflito a partir do uso explícito de termos racializantes, não permite que cheguemos à conclusão de que o insulto institucionalize a possibilidade de "fazer o insultado retornar a um lugar inferior já historicamente constituído" (p. 194). No limite, parece que o autor se apropria da forma de um discurso social extra-legal, "o insulto racial", para descrever e informar um processo de institucionalização de pretensões de inferiorização. A circularidade do raciocínio, contudo, não compromete a importância de cada um dos pólos desse processo, apenas chama a atenção sobre as inúmeras possibilidades abertas pela riqueza do material levantado e para a complexidade social interna às relações pautadas pelo insulto. Suspendendo, ainda que momentaneamente, suas conclusões, aceita-se o convite proposto pelo próprio autor para participar ativamente no debate vivo plasmado neste e em outros volumes escritos por Antônio Sérgio Guimarães.

De alguma forma, seu trabalho indica uma forte tendência a um reencontro das ciências sociais com momentos decisivos de sua história, agora em outros termos, pois deparamo-nos com uma sociedade que passou por um recente processo de democratização e que agora, mais do que nunca, olha para a academia não apenas à espera de soluções, mas com a expectativa daqueles que exigem um tratamento pautado por noções de igualdade - isto sim, algo, até agora, alheio à nossa tradição histórica.

\section{NOTAS}

1 Cf. "Democracia racial: o mito e o desejo", mesa-redonda, Folhetim, Folha de S. Paulo, 8/6/1980

2 Vicent Capranzano, Wainting: the whites of South Africa, Londres, Granada, 1985.

OMAR RIBEIRO THOMAZ é professor do Departamento de Antropologia da Unicamp e pesquisador do Centro Brasileiro de Análise e Planejamento e do Núcleo de Pesquisa sobre o Ensino Superior. 